\title{
Organic synthesis reactions on-water at the organic-liquid water interface
}

Richard N. Butler ${ }^{a_{*} \dagger}$ and Anthony G. Coyne ${ }^{b_{*}}$

${ }^{a}$ School of Chemistry, National University of Ireland, Galway, Ireland. ${ }^{b}$ Department of Chemistry, University of Cambridge, Lensfield Road, Cambridge CB2 1EW, United Kingdom.

*agc40@cam.ac.uk

\section{Abstract}

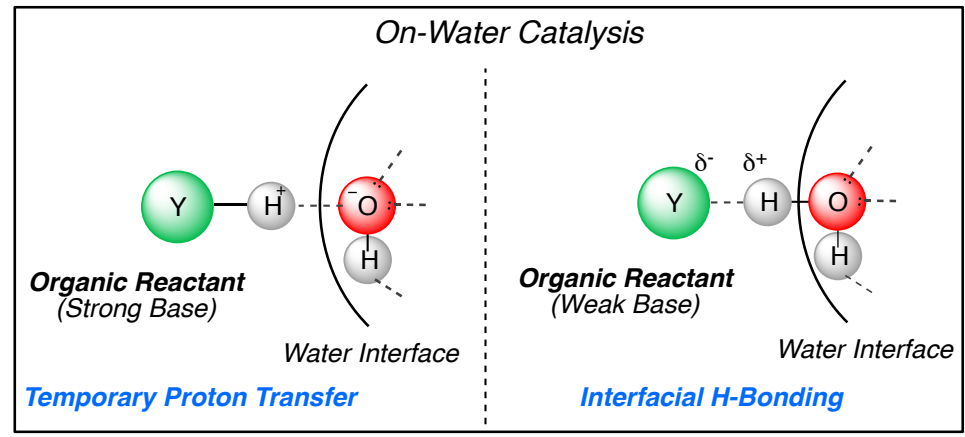

The combination of organic reactions on-water, that occur at the water interface for water-insoluble compounds, and reactions in water solution for water soluble compounds, has added a powerful dimension to prospects for organic synthesis under more beneficial economic and environmental conditions. Many organic molecules are partially soluble in water and reactions that appear as heterogeneous mixtures and suspensions may involve on-water and in-water reaction modes occurring simultaneously. The behavior of water molecules and organic molecules at this interface is discussed in the light of reported theoretical and experimental studies. The on-water catalytic effect, relative to neat reactions or organic solvents, ranges from factors of several hundred times to 1-2 times and it depends on the properties of reactant compounds. In some cases when on-water reactions produce quantitative yields of water-insoluble products they can reach ideal synthetic aspirations.

\section{Introduction}

Many organic reactions can be carried out in the water medium even when the reactants are highly insoluble in water. Such water promoted reactions between water-insoluble reactants were named on-water reactions by Sharpless, Fokin and co-workers who drew attention to this phenomenon in 2005 (Scheme 1 and 2). ${ }^{1}$ In earlier seminal work Breslow and co-workers explored the Diels-Alder cycloadditions and many other reactions in water solution and identified and established the hydrophobic effect as the central driving force facilitating organic reactions in water solutions. ${ }^{2-4}$ The 
powerful combination of both in-water and on-water modes for reactions in the water medium has developed into a huge domain for organic synthesis in recent years. ${ }^{5-12}$

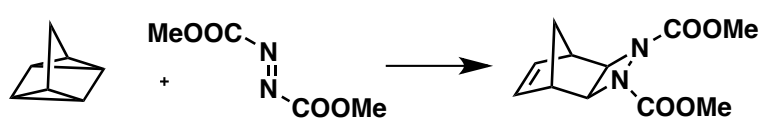

1

2

3

\begin{tabular}{cccc}
\hline Solvent & Conc [M] & Time to completion & Conversion Yield (\%) \\
\hline Neat & 4.53 & $48 \mathrm{~h}$ & 85 \\
$\mathrm{H}_{2} \mathrm{O}$ & 4.53 & $10 \mathrm{~min}$ & 82 \\
$\mathrm{D}_{2} \mathrm{O}$ & 4.53 & $45 \mathrm{~min}$ & 82
\end{tabular}

Scheme 1: Cycloaddition reaction of quadricyclane and dimethyl azodicarboxylate under neat conditions, $\mathrm{H}_{2} \mathrm{O}$ and $\mathrm{D}_{2} \mathrm{O}$ at $23^{\circ} \mathrm{C} .^{1}$

\begin{tabular}{cccc} 
& & & \\
\hline Solvent & Conc [M] & Time (h) & Yield (\%) \\
Toluene & 1.0 & 120 & \\
neat & 3.88 & 72 & 86 \\
On $\mathrm{H}_{2} \mathrm{O}$ & 3.88 & 12 & 86
\end{tabular}

Scheme 2: Nucleophilic ring-opening of epoxides.

An essential physical requirement for on-water reactions of water-insoluble organic reactants is the presence of a liquid organic oily-phase which interfaces with the bulk water layer. Herein the term 'on-water reaction' applies to organic reactions that occur between water insoluble reactants at the interface of a bulk liquid water phase that contains no additives. It does not apply to reactions in the presence of very small quantities of water, such as hydrated salts, ${ }^{13}$ or involving other catalysts. If the organic reactants are solids at least one must be liquefied in order to produce this organic oily layer. ${ }^{14,15}$ Liquefaction is amenable for solids with melting points lower than the boiling point of water. Higher 
melting unreactive solid-solid reactions have recently been brought into the range of on-water chemistry by McErlean and co-workers. They used the unique dissolving power of ionic liquids to provide a liquidwater interface containing the organic reactants with no need for organic co-solvents. ${ }^{16}$ For example the reaction of the solids anthracene-9-carbinol $\mathbf{7}$ and dimethyl fumarate $\mathbf{8}$ was successful on-water with the ionic liquid [BMIM][NTf 2$]$ but failed under neat or normal on-water conditions (Scheme 3).

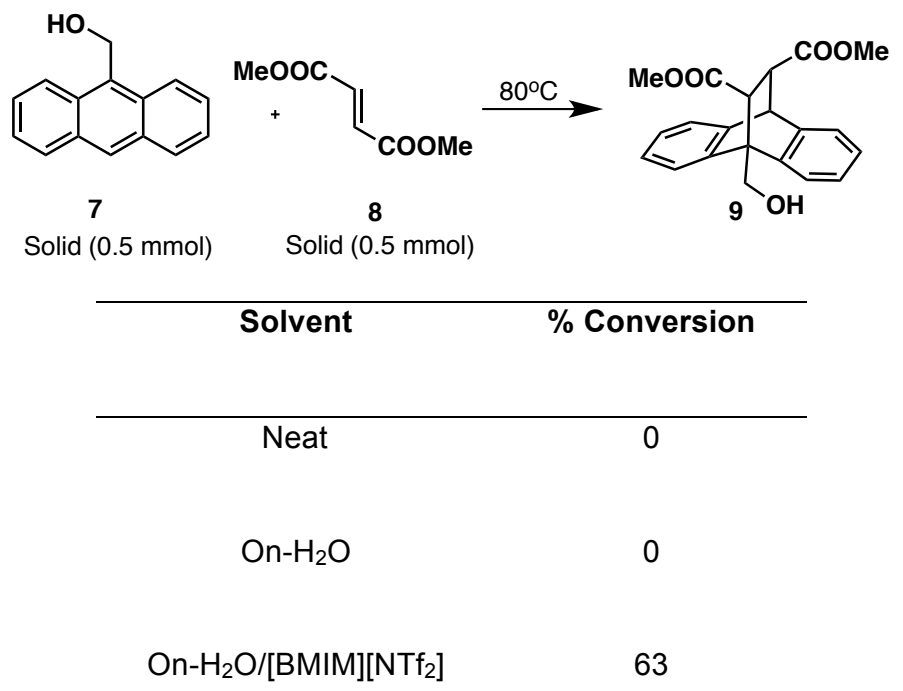

Scheme 3: Solid-Solid on-water reactions. ${ }^{16}$

With the developments of the past decade since the term 'on-water' first appeared, the scene is set for significant growth in the application of this approach to more economical and environmentally acceptable chemical synthesis.

\section{Identifying On-water reactions}

Significant numbers of reactions in the literature have been classified as on-water by virtue of the appearance of heterogeneous mixtures in the reaction flasks. Such a pointer to designate an onwater reaction is unreliable. The division between in-water reactions where the transition state occurs in the bulk water medium, and on-water reactions, where the transition state occurs at the organic side of the organic-water interface is blurred in most cases where the reactants are partially soluble in water. The appearance of the two reactions shown in Scheme 4 illustrates this. Reaction $A$ is an in-water reaction and Reaction $B$ is an on-water case. The visual appearances of these reactions are highly indistinguishable and do not allow a distinction between the in-water and on-water reaction modes. The 1,3-dipole reactant 10 is highly water insoluble but is carried through the water solution by the solubility of 2-cyclopentene-1-one $11\left(\mathrm{~s}=0.27 \mathrm{~mol} \mathrm{~L}^{-1}\right)$. The endo:exo ratio of the products 12 and 13 increases from 5:1 in MeCN to 42:1 in water because the reaction experiences the Breslow hydrophobic effect of 
bulk water which strongly increases the endo:exo product ratio for in-water cycloadditions, when reactants have significant hydrophobic surface areas. ${ }^{3,4}$ The lesser solubility of 1-octene-3-one, 14 (s = $0.016 \mathrm{~mol} \mathrm{~L}^{-1}$ ), which also has a large hydrophobic surface area, changes the reaction to the on-water mode. The endo:exo ratio of the products 15 and 16 is the same in MeCN and water $(8.4 \pm 0.2)$ because this reaction does not experience the hydrophobic effect of bulk water. ${ }^{17,18}$ Its transition state is on the organic side on the organic-water interface. For cycloaddition reactions the endo:exo ratio of the cycloadduct products can be a useful parameter to distinguish the on-water and in-water modes.

(a)



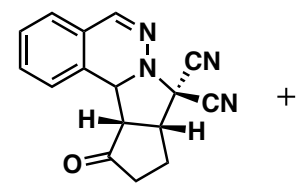

12

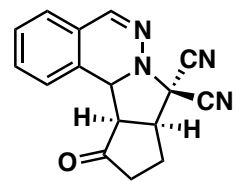

13

(b)<smiles>CCCCCC(=O)[C@H]1C[C@@](C)(N)N2N=Cc3ccccc3C1[C@@H]2c1ccccc1</smiles>
$\left(s=0.016 \mathrm{molL}^{-1}\right)$
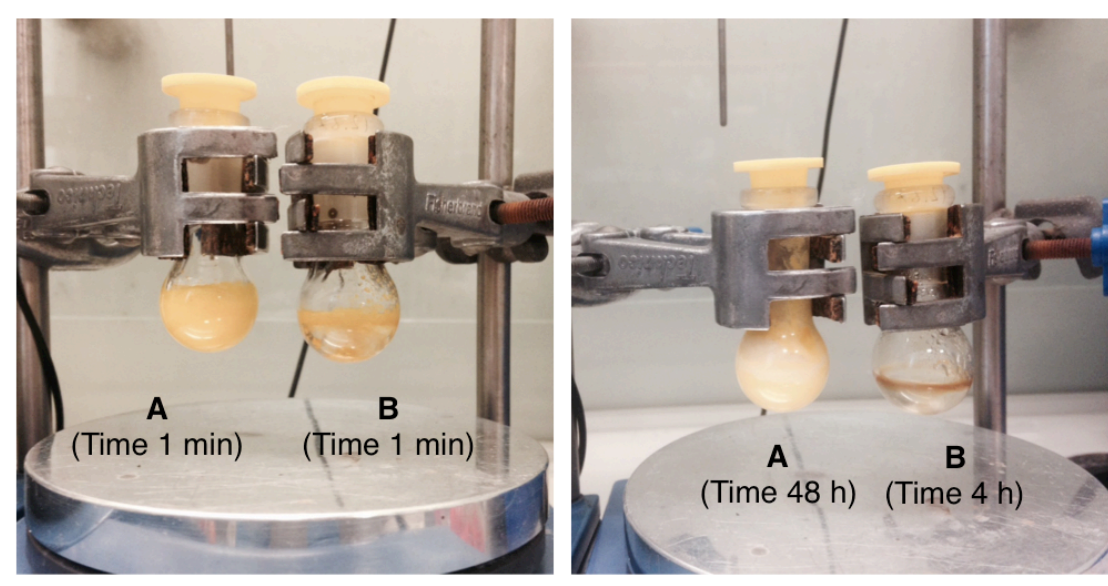

Scheme 4: Visual appearance of in-water $(A)$ and on-water $(B)$ reactions ( $s=$ water solubility). ${ }^{18}$

Further experimental parameters are required for the many reactions that do not allow for such a stereochemical distinction between on-water and in-water reactions. In all cases close attention needs to be paid to reactant water solubilities as guidelines for reactions being carried out in the water medium. Only limited thermodynamically measured water solubilities of organic compounds are available, but in recent years computational methods for water solubilities of organic compounds have greatly improved in reproducing experimental measurements. ${ }^{19,20}$ Computed solubilities for the vast 
range of organic compounds within the CAS register can be obtained using SciFinder ${ }^{\mathrm{TM}}$. They provide an invaluable database used by the chemical and medicinal/pharmaceutical communities and are essential for anyone interested in the on-water phenomenon. From a study of a wide range of cycloaddition reactions such as those shown in Fig. 1 and other reported reactions we have found that cases involving organic compounds with water solubility $<0.01 \mathrm{~mol} \mathrm{~L}^{-1}$ are likely to be on-water. When one of the reactants has water solubility an order of magnitude higher, $>0.1 \mathrm{~mol} \mathrm{~L}^{-1}$, the reaction tends to occur by the in-water mode. ${ }^{17,18}$ In all cases these reactions appear as heterogeneous mixtures of reactants and products. For reactants that are partially soluble in water both the on-water and in-water modes of reaction may be occurring simultaneously with one or other dominant. Because of the wide range of water solubilities of organic compounds there is no sudden change of reactions from in-water to on-water. In Fig. 1, the available results are used to provide a guideline of the gradual changes that arise as organic reactions in-water respond to increasing water insolubility by changing from clear solutions of in-water reactions to heterogeneous mixtures involving in-water and on-water modes and finally to fully on water reactions of highly insoluble reactants. The reactant with the highest water solubility determines where a reaction fits along this spectrum.

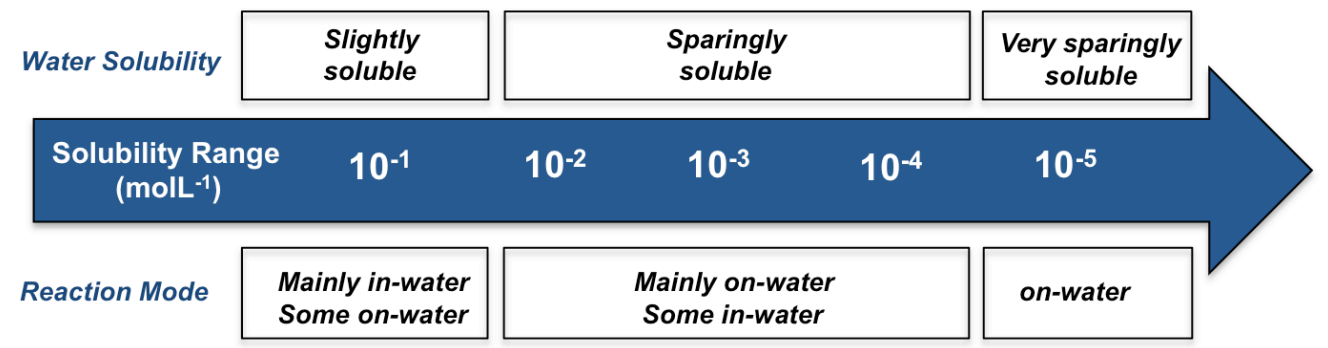

Fig. 1: Gradual transition to on-water reactions with falling reactant water solubility

Pirrung and coworkers have shown that the yields and efficiency of on-water reactions, e.g. the Passerini reaction (Scheme 5), are influenced by the physical mixing parameters such as stirring speeds, shaking and ultrasonication. ${ }^{21}$
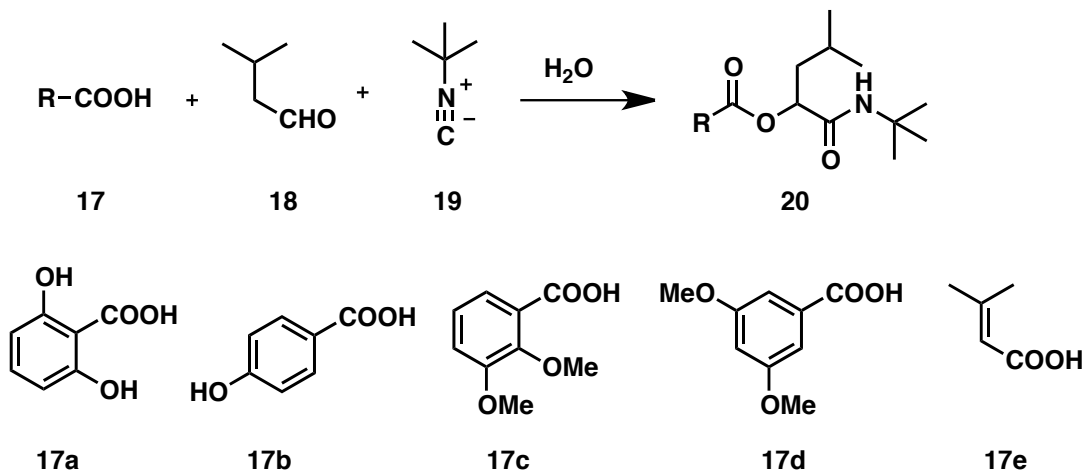
Scheme 5: Passerini three-component reaction on-water ${ }^{21}$

These influence the volume and surface area of organic droplets and hence comparative studies of onwater organic reactions require standardization of the physical characteristics of the reaction system. Stirring and agitation effects are not essential for on-water catalysis but they contribute by refreshing and regenerating the surfaces at the interface by removing products and lone reactant molecules that are embedded. ${ }^{22,23}$ On-water reactions of quadricyclane with diethylazodicarboxylate (DEAzD) were observed when static droplets of the mixture, surrounded by water, were held rigidly in capillaries without agitation. $^{22}$ The nature of normal laboratory scale on-water reaction conditions that involve stirring a mixture of two or more immiscible phases of insoluble reactants and products prevents reproducible control of surface areas, surface to volume ratios and droplet sizes in the mixtures. Hence normal kinetic data are absent for many on-water organic synthetic reactions. Huck and co-workers have overcome this difficulty for two reactions of diethylazodicarboxylate (DEAzD) (see section 3.1$){ }^{23}$

\section{On-water effects at the bulk-water interface}

Three main effects influence the outcome of organic reactions in bulk water solution, the hydrophobic effect, hydrogen bonding and the polarity of water as a solvent. ${ }^{3,4,24-29}$ Breslow established the reaction enhancing hydrophobic effect as the central driving force for organic reactions in water solution. ${ }^{3,4}$ creates aggregates of organic molecules in water solution with energies raised closer to reaction transition states. ${ }^{3,4,24,25}$ The transition state energies are not similarily raised by the hydrophobic effect. Engberts has shown that the reactive sites of transition state complexes in water solution lose their hydrophobic character and become compatiable with the water medium due to the polarizable nature of the electronic changes that are occurring in the bonds at the reactive sites. ${ }^{24,25}$

When reactions change from the realm of the bulk water solution to the water-insoluble realm at the water-organic interface hydrogen bonding effects provide the main reaction driving force and the hydrophobic effect plays a lesser role. A significant feature of the hydrophobic effect for reactions dissolved in the bulk water medium is enhancement of the product endo/exo ratios for Diels-Alder and Huisgen cycloaddition reactions. The sterically more compact endo-transition state, with reduced hydrophobic surface area, are significantly favoured in water solution. This endo-isomer enhancement does not arise for the insoluble on-water reactions that take place at the organic-water interface. ${ }^{17,18}$ Using Quantum Mechanical/Molecular Modeling (QM/MM) of the Claisen rearrangements Acevedo and Armacost found that transition states were stabilized by interfacial $\mathrm{H}$-bonding with negligible hydrophobic contributions, Scheme $6 .^{30}$ 
(a)<smiles>[R]c1ccc(OCC=C)cc1</smiles>

21<smiles>[R]C1=CC(CC)C(=O)C=C1</smiles>

22<smiles>[R]c1ccc(O)c(CC=C)c1</smiles>

23

(b)<smiles>C=CC(C)(C)Oc1ccc(Cl)c2ccccc12</smiles>

Scheme 6: Claisen rearrangement (QM/MM modeled $)^{30}$

On-water effects for water insoluble organic reactions, relative to neat conditions and solutions in nonpolar organic solvents, range from mild reaction enhancements, with competition times reduced by $\sim 10$ 300 times. In the first theoretical study of the on-water effect Jung and Marcus proposed that the main source of on-water catalysis arose from interfacial hydrogen bonding by dangling $\mathrm{OH}_{\text {free }}$ groups at the water interface to $\mathrm{H}$-bond acceptor sites in organic transition states that are embedded in the water surface. ${ }^{31}$ Jorgensen and co-workers carried out a QM/MM assessment of the on-water effect for three Diels-Alder reactions of cyclopentadiene 27 with 1,4-naphthaquinone 28 (Scheme 7), methyl vinyl ketone and acrylonitrile, in the gas phase, at the water-vacuum interface (representing on-water) and in bulk water solution. ${ }^{32}$ The on-water activation energies were intermediate between the values for the gas phase and the bulk water solution. The cycloaddition with 1,4-naphthaquinone 28 was more deeply embedded into the water interface. ${ }^{32}$

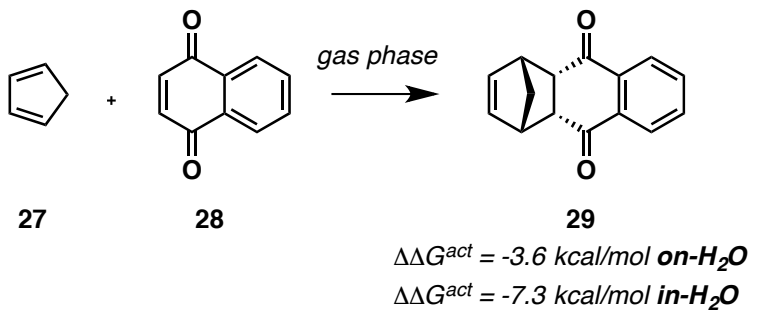

Scheme 7: Diels-Alder reaction of cyclopentadiene and a naphthaquinone. ${ }^{32}$

\subsection{Mild on-water catalysis effects: H-bonding at Water-Organic Interfaces}

The cycloadditions of quadricyclane with dialkyl azodicarboxylates are reactions that span the range of on-water catalytic effects. The completion time for the reaction with dimethylazodicarboxylates (DMAzD), Scheme 1, was reduced from 48 hour to $10 \mathrm{~min}$. on changing from neat conditions to onwater. ${ }^{1}$ The general reaction has attracted considerable attention. In a comprehensive study Zuo and 
Qu found that all of the on water reactions worked better with larger volumes of water present (e.g. 100 $\mathrm{mL}$ versus $12 \mathrm{~mL}$ ) for fixed quantities of reactants, and small quantities of water were ineffective, (Scheme 8). ${ }^{33}$ Increased sizes for the alkyl substituents in each of the reactions reduced the on-water effect. The authors concluded that a minimum level of water solubility was necessary for successful onwater reactions. $^{33}$

(a)

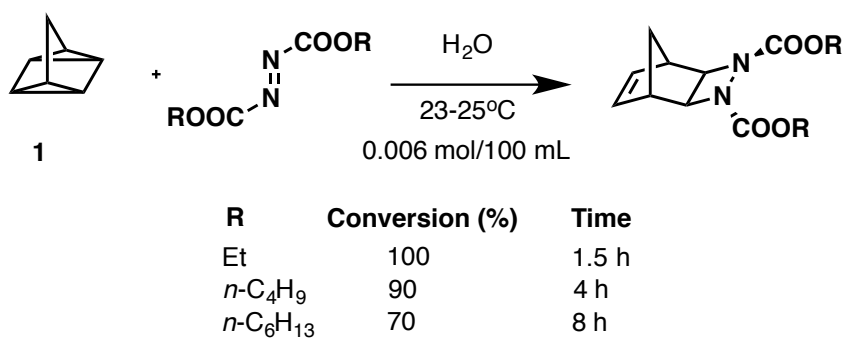

(b)

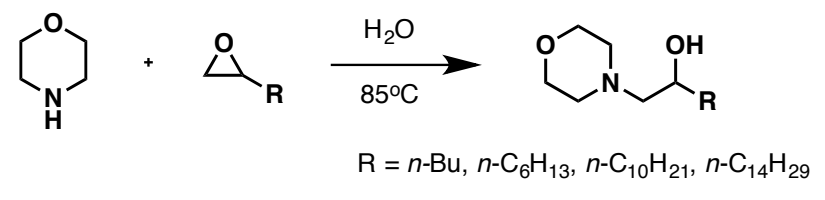

30

31

32

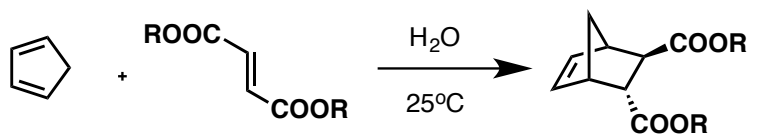

$\mathrm{R}=\mathrm{Et}, n-\mathrm{Bu}, n-\mathrm{C}_{8} \mathrm{H}_{17}, n-\mathrm{C}_{12} \mathrm{H}_{25}$

27

33

34

Scheme 8. On-water reactions. ${ }^{33}$

These results may reflect the importance of embedding of the reactants from the organic layer into the water surface at the phase interface. In fundamental work Huck and co-workers quantified the on-water effect per unit area of water surface for the cycloaddition reaction of DEAzD with quadricyclane and the ene-reaction with $\beta$-pinene 35 , (Scheme 9 ). ${ }^{23} \mathrm{~A}$ biphasic microfluidic platform was set up using a crossjunction meeting of controlled flows of water and toluene solutions of the organic reactants. Fast camera imaging provided lengths, surface areas and volumes at the water organic interface. Linear relationships of reaction conversions with the water surface area were recorded and regular sampling combined with NMR analysis provided Arrhenius data and rate constants (Scheme 9). ${ }^{23}$ 
(a)

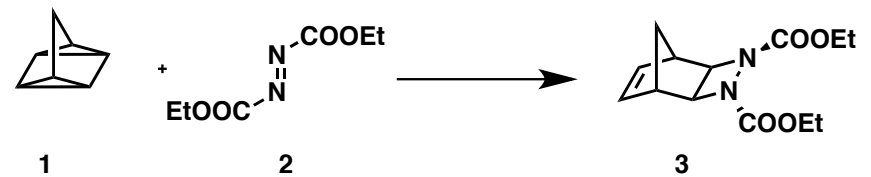

$$
\begin{array}{ccccc}
\begin{array}{c}
\mathbf{E}_{\text {act }} \\
\mathrm{C}_{6} \mathrm{H}_{5} \mathrm{CH}_{3} \\
\left(\mathrm{kcal} \mathrm{mol}^{-1}\right)
\end{array} & \begin{array}{c}
\mathbf{k} \\
\mathrm{C}_{6} \mathrm{H}_{5} \mathrm{CH}_{3} \\
\left(\mathrm{Lmol}^{-1} \mathrm{~s}^{-1}\right)
\end{array} & \begin{array}{c}
\mathbf{E}_{\text {act }} \\
\mathrm{H}_{2} \mathrm{O}
\end{array} & \begin{array}{c}
\mathbf{k} \\
\left(\mathrm{kcal} \mathrm{mol}^{-1}\right)
\end{array} & \begin{array}{c}
\mathrm{K}_{2} \mathrm{O} \\
\left(\mathrm{Lmol}^{-1} \mathrm{~s}^{-1}\right)
\end{array} \\
\\
9.3 \pm 1.3 & 1.6 \times 10^{-6} & 3.9 \pm 0.4 & 1.3 \times 10^{-5} & 1.1-1.2
\end{array}
$$

(b)

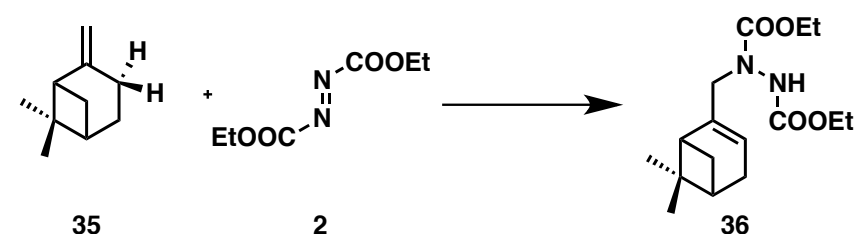

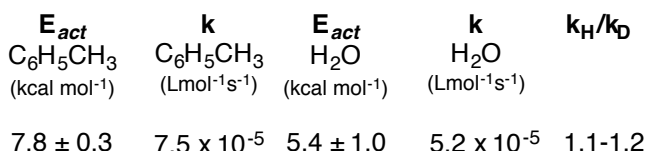

Scheme 9. Comparative data for reactions on-water and in toluene solutions. ${ }^{23}$

The reactions showed small deuterium isotope effects for on- $\mathrm{H}_{2} \mathrm{O}$ and on $-\mathrm{D}_{2} \mathrm{O}$, with $\mathrm{k}_{H} / \mathrm{k}_{\mathrm{D}}=1.1-1.2$, (Scheme 9). ${ }^{23}$ The experientially measured fall in the activation barrier for the reaction of DEAzD with quadricyclane of $5.4 \mathrm{kcal} . \mathrm{mol}^{-1}$ on changing from toluene solution to on-water agreed with the value of 7.5 kcal.mol ${ }^{-1}$ predicted by Jung and Marcus. ${ }^{23,31}$ Huck's work also agrees with that of Ben-Amotz and co-workers who have shown that the appearance of dangling $\mathrm{OH}_{\text {free }}$ groups at a water-organic (hydrophobic) interface is a cooperative process that increases with the area and the electrostatic nature of the surface. ${ }^{34}$ When the organic reactants contain $\mathrm{H}$-bond acceptor sites (negative polarity) at the interface, the water surface has the capacity to adjust the distribution of positive sites $\left(\mathrm{OH}_{\text {free }}\right.$ groups) to match. Deuterium isotope effects similar to those measured by Huck have been reported for the Huisgen cycloaddition of 1 -octene-3-one 14 , with phthalazinium dicyanomethanide $10, \mathrm{k}_{H} / \mathrm{k}_{\mathrm{D}}=1.08$ (Scheme 10), and for the reaction of cyclopentadiene 27 with diethylacetylene dicarboxylate (DEAD), ${ }^{18,35}$ In the latter case the value at 1.4 at ca $50 \%$ conversion and for $100 \%$ completion times on- $\mathrm{H}_{2} \mathrm{O}$ and on $-\mathrm{D}_{2} \mathrm{O}$ were the same. ${ }^{35}$ Primary $\mathrm{H} / \mathrm{D}$ effects for a linear $\mathrm{H}$-atom transfer between two atoms in a transition state display values of $5-7 .^{36 a}$ These low deuterium isotope values indicate that hydrogen bonding rather than proton transfer, is the source of the mild catalytic effects observed in many on-water reactions in agreement with a number of theoretical studies. ${ }^{30-32,37}$ 

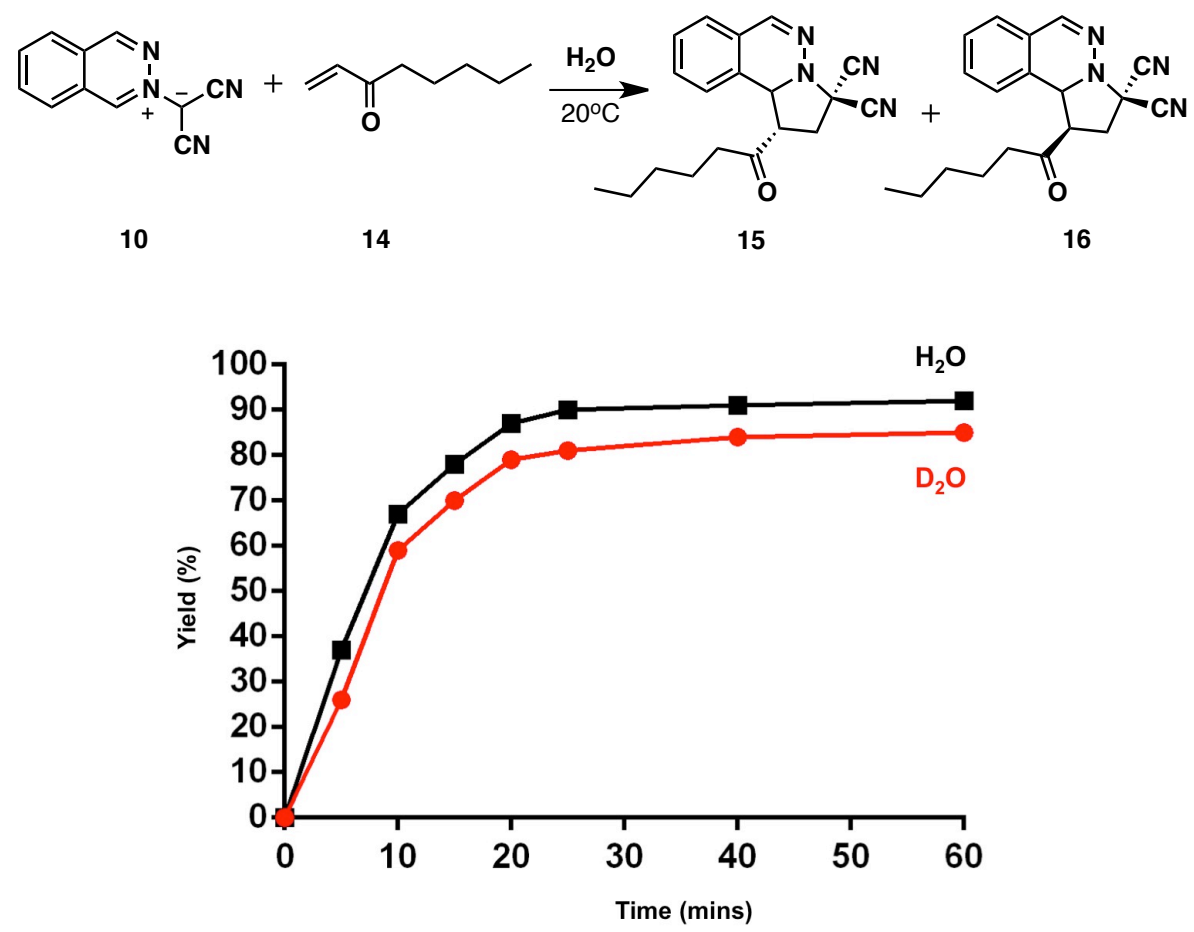

Scheme 10. Comparison on the cycloaddition reaction of phthalazinium-2-dicyanomethanide 10 and 1octene-3-one 14 on $\mathrm{H}_{2} \mathrm{O}$ (black) and $\mathrm{D}_{2} \mathrm{O}$ (red).

\subsection{Strong on-water catalysis effects: Proton transfer at water-organic interfaces.}

A number of reactions have been reported that display strong on-water catalytic effects. These reactions exhibit primary deuterium isotope effects for some basic organic nitrogen substrates and they include displacements of $\mathrm{OH}$ groups at benzylic and allylic sites and epoxide ring opening in the absence of any added acids or catalysts in the water phase. Beattie and co-workers first suggested that proton transfer could be the source of such on-water catalysis and they pointed out that the interfacial surface layer of bulk liquid water in contact with the low dielectric constant materials has a propensity for holding negative charge and $\mathrm{OH}^{-}$ions. ${ }^{35,38,39}$

\section{(a) Organic nitrogen Systems}

The synthetic significance of the aza-Claisen rearrangement was recently highlighted by McErlean and Beare when they used on-water conditions to synthesise the naphtha[c]isoxazole heterocyclic scaffold $39 .^{40}$ This is an isomeric analogue of the benzo[d]isoxazole system that is present in several commercial pharmaceuticals including the anti-convulsant zonisamide $\mathbf{4 0}$ (Scheme 11). ${ }^{40}$ The on-water Claisen rearrangement of reverse $\mathrm{N}$-prenylated anilines and naphthylamines, 7, was successful at $80^{\circ} \mathrm{C}$, obviating the temperatures of $200-300^{\circ} \mathrm{C}$ necessary for the thermal rearrangement, and making the reaction accessible for a wide range of substrates. The reaction that occurred on-water was not successful in toluene or ethanol and it was significantly slowed on- $\mathrm{D}_{2} \mathrm{O}$, (Scheme 11). 
<smiles>CC(C)(C)Nc1cccc2ccccc12</smiles>

37

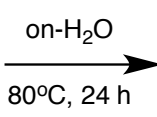

$80^{\circ} \mathrm{C}, 24 \mathrm{~h}$

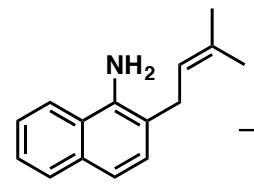

38<smiles>CC(C)=Cc1onc2c1ccc1ccc(CC(C)C)cc12</smiles>

39

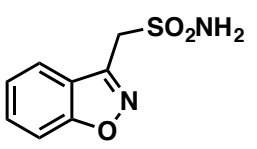

Zonisamide

40

Scheme 11. Aza-Claisen rearrangement on-water. ${ }^{40}$

Measurements of substituent effects para to the amino group and comparative rate plots for reactions on- $\mathrm{H}_{2} \mathrm{O}$ and on $-\mathrm{D}_{2} \mathrm{O}\left(\mathrm{k}_{\mathrm{H}} / \mathrm{k}_{\mathrm{D}} \sim 6\right)$ indicated that the reaction involved a proton transfer at the waterorganic interface. The reaction was explained in terms of an interfacial proton transfer leading to an autocatalytic cycle, (Scheme 12). ${ }^{40}$

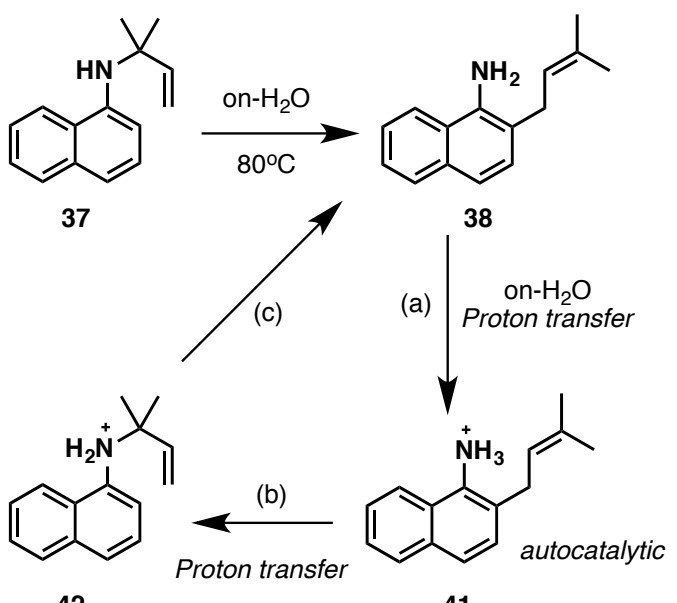

42

41

Scheme 12: Aza-Claisen rearrangement on-water ${ }^{40}$

A significant deuterium isotope effect $(\sim 4.5)$ in the reaction of dimethyl azodicarboxylate, 2 with quadricyclane at $23^{\circ} \mathrm{C}$ on-water (Scheme 1) indicates that this is strongly catalysed reaction involves a proton transfer at the organic-water interface. Domingo and co-workers modeled the reaction in the gas phase and with two molecules of water. The water molecules lowered the activation barrier from 23.2 to $14.7 \mathrm{kcal} \mathrm{mol}^{-1}$ in a polar mechanism with strong zwitterionic character. ${ }^{41}$ Quadricyclane acted as a nucleophile and DMAzD as an electrophile on a mechanism that is compatible with a proton transfer to the azo-nitrogen in a transition state that is deeply embedded into the water interface, (Figure 2). 


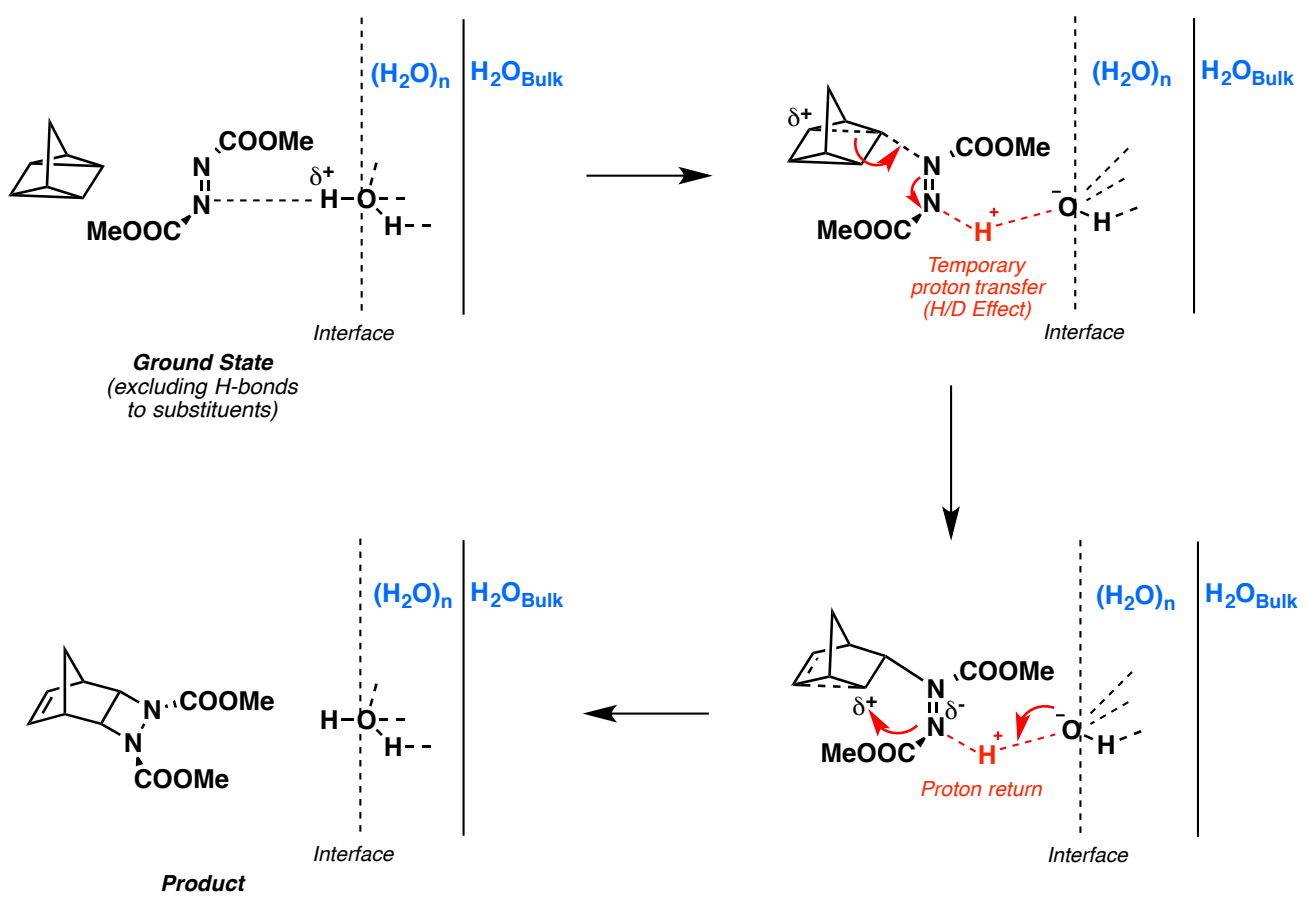

Figure 2: On-water reaction of quadricyclane with dimethylazodicarboxylate with a zwitterionic transition state.

(b) Organic oxygen systems

Replacements of $\mathrm{OH}$ groups from water insoluble hydroxyl compounds by water-insoluble nucleophiles, in the absence of any catalysts, adds a significant dimension to on-water organic chemistry (Scheme 13). ${ }^{42}$ 
General conditions

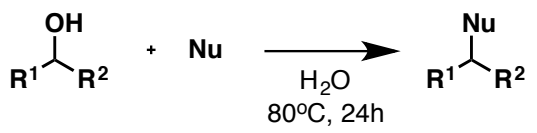

(a)

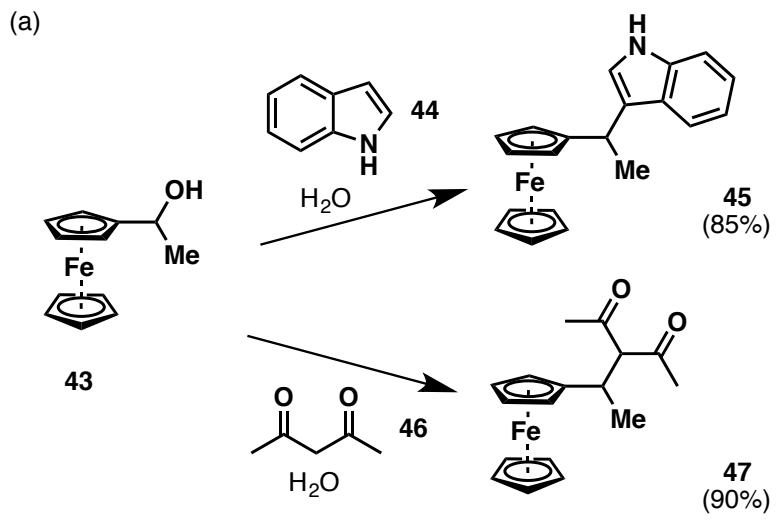

(b)<smiles>OC1c2ccccc2Sc2ccccc21</smiles>

48

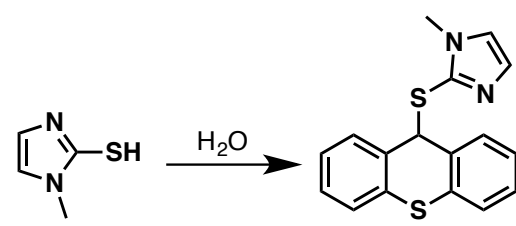

49

Scheme 13. On-water nucleophilic replacements of $\mathrm{OH}^{42}$

The efficiency of these reactions has been attributed to the stability of carbocations generated from the hydroxyl compounds for example the on-water reaction of indole 44 (water solubility $16 \mu \mathrm{M} \mathrm{mL}^{-1}$ ) with the water insoluble ferrocenyl alcohol $\mathbf{4 3}$ produced a high yield of 3-substituted indole derivatives $\mathbf{4 5}$ in a 24 hour reaction. ${ }^{42}$ Stable carbocation intermediate were considered necessary because highly reactive carbocations were too rapidly quenched by water before reactions with other nucleophiles could take place.

Intramolecular examples of on-water $\mathrm{OH}$ replacement reactions, with no added catalysts, are shown in Scheme $14{ }^{43}$ Stabilised carbocations are also considered to be involved in these cyclisations. ${ }^{43}$ On-water trans-phase protonation of the $\mathrm{OH}$ group followed by nucleophilic displacement of the $-{ }^{+} \mathrm{OH}_{2}$ leaving group in favored Baldwin cyclisations could also account for some of these reactions (Scheme 14). 
General conditions

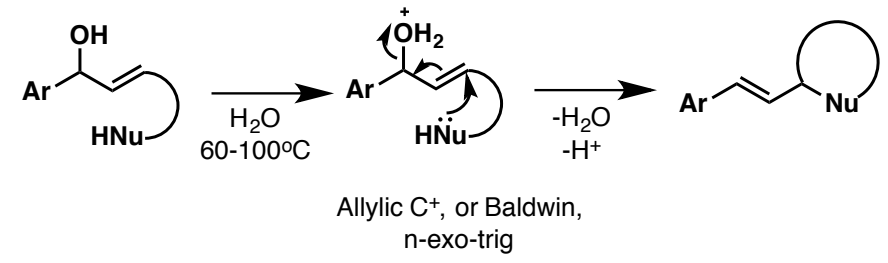

(a)

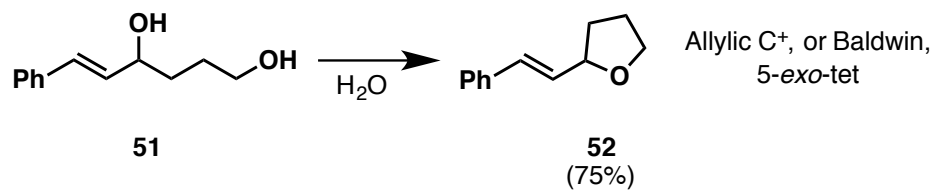

(b)<smiles>Oc1ccccc1C(O)/C=C/c1ccccc1</smiles>

53<smiles>CC(C)OCCO</smiles>

54
Allylic $\mathrm{C}^{+}$, or Baldwin, 5-endo-trig

Scheme 14. Cyclisations, intramolecular on-water replacement of $\mathrm{OH}$ groups. ${ }^{43}$

Proton transfer at the water-organic interface, or exceptional $\mathrm{H}$-bonding effects, are essential for the $\mathrm{OH}$ displacement reactions. On-water promoted ring openings of epoxides, without added acid or catalysts, are further examples of reactions where proton transfer at the water-organic interface may be involved. For example stirred suspensions of (-)- $\alpha$-pinene oxide 55 in water at $20^{\circ} \mathrm{C}$ for $6 \mathrm{~h}$ gave a $75 \%$ yield of trans-(-)-sobrerol 56 (er 99:1, no cis product), in a reaction that involves a carbocation intermediate, Scheme $15{ }^{44}$ At higher temperatures the reaction was more complicated with secondary products and further reactions of the sobrerol product $\mathbf{5 6 .}$

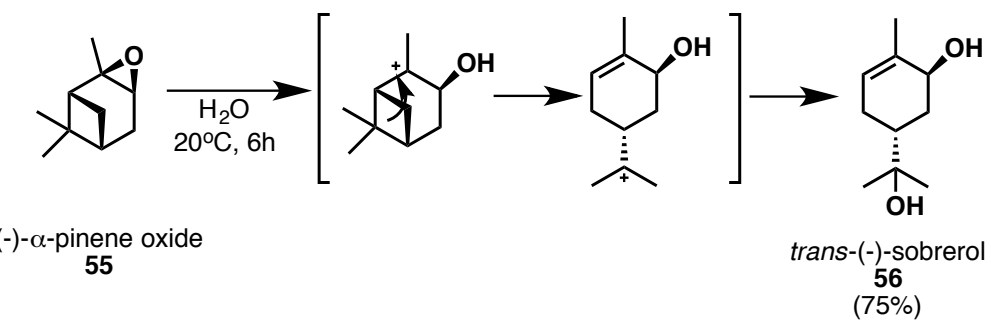

Scheme 15. Ring opening of $\alpha$-pinene oxide. ${ }^{44}$

The transition states of on-water reactions are required to be well embedded into the water surface at the organic-water interface. The examples discussed show that the presence of large hydrocarbon (hydrophobic) substituents as well as weak basicity in the organic reactants lower the capacity for on-water catalysis. Organic reactions that have basic atoms located in bonds undergoing electronic changes at the core of the transition state are the most likely to benefit from strong on-water effects. Alkyl arylamines and organic azo compounds are significant bases with basic $\mathrm{pK}_{\mathrm{a}}$ values in the 
range 2-5 ( $\mathrm{pK}_{\mathrm{a}}$ of conjugate acid) ${ }^{36 \mathrm{~b}}$ Each of the reactions in Schemes $12-15$ involves the breaking of a covalent bond at a basic $\mathrm{H}$-bond acceptor atom in the transition state of the on-water reaction.

\subsection{Synthetic organic reactions on-water reactions}

The use of on-water conditions in organic synthesis is ever increasing and the aim of this section is to illustrate the scope of reactions which have been examined. This is not meant to be a complete list and more in depth discussions can be found throughout the literature. ${ }^{5-10}$

\section{(a) Cycloaddition reactions}

The initial focus for on-water reactions concentrated on pericyclic reactions, where the major advantage was that it was mechanistically easier to rationalize the effects observed. When 1,3-dipole 10 was reacted with 4-chlorobenzylidineacetone $\mathbf{5 7}$ using on-water conditions at room temperature, no reaction was observed. Upon heating at $40^{\circ} \mathrm{C}$ only a small amount of product was formed $(\sim 3 \%) .{ }^{45} \mathrm{On}$ further increasing the reaction temperature to $75^{\circ} \mathrm{C}$ the product was formed in $75 \%$ yield over 24 hours. When diphenylacetylene 59 was used as the dipolarophile with 1,3-dipole 10, <1\% product was formed at $20^{\circ} \mathrm{C}$ but when heated at $81^{\circ} \mathrm{C}$, the product was formed in $71 \%$ yield (Scheme 16$) .{ }^{14,45}$ In both of these cases the reactants are highly insoluble solids and only undergo reaction when one of the reactants is liquefied above the melting point. ${ }^{45}$ When the 1,3-dipole 10 was reacted with a range of maleimide dipolarophiles 61 at room temperature the reaction occurred in yields greater than $93 \%$. All the maleimide dipolarophiles are solids and the reaction readily occurs at room temperature where the products can be isolated by filtration as a white solids. 
(a)<smiles>CC(C)=CC(=O)C(C)O</smiles>

57

(b)<smiles>N#CC(C#N)[n+]1cc2ccccc2cn1</smiles>

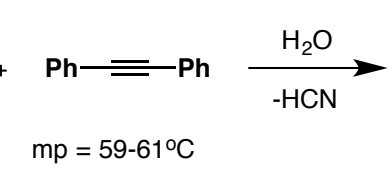

59<smiles>N#Cc1c(-c2ccccc2)c(-c2ccccc2)n2ncc3ccccc3c12</smiles>

60

(c)<smiles>N#CC(C#N)[n+]1cc2ccccc2cn1</smiles>

10<smiles>[X]c1ccc(N2C(=O)C=CC2=O)cc1</smiles>

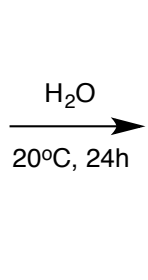

61

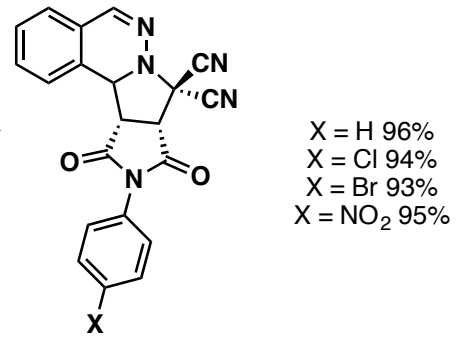

62

$20^{\circ} \mathrm{C},<1 \%(24 \mathrm{~h})$ $81^{\circ} \mathrm{C}, 71 \%(24 \mathrm{~h})$

Scheme 16. On-water Huisgen cycloaddition reactions of phthalazinium-2-dicyanomethanide with a range of solid dipolarophiles. ${ }^{45,14}$

Palacios and co-workers examined the inverse electron demand Diels-Alder 4+2 cycloaddition reaction of nitroso alkenes with electron rich vinyl ethers. ${ }^{46}$ The nitroso diene was generated in situ from the corresponding phosphorylated hydroxylamine under base catalysed conditions. Under solvent free conditions, using triethylamine as base, the oxazine products were isolated in yields of up to $94 \%$ and in a diastereoselective ratio of $1: 1$ to $0: 1$. When the subsequent reactions were carried out using on-water conditions the yields were found to be up to $95 \%$ and the selectivity of the reaction gave predominantly one diastereoisomer however, the reaction time decreased from 30 minutes to 18 hours.

Román and co-workers explored the Diels-Alder cycloaddition reaction of $\mathrm{N}$-alkyl and $\mathrm{N}$-aryl substituted maleimides with substituted furan derivatives using the on-water conditions. ${ }^{47}$ The reactions were carried out at both room temperature and at $65^{\circ} \mathrm{C}$. In all cases the starting materials were either insoluble or slightly soluble in water forming an aqueous suspension upon vigorous stirring. At $25^{\circ} \mathrm{C}$ the stereoselectivity of the products of the reaction were predominantly endo however upon heating to $65^{\circ} \mathrm{C}$ an increase in the exo selectivity was observed showing that the diastereocelectivity of the reaction could be controlled using varying temperatures. 
The on-water approach to industrial organic synthesis can provide significant economic and environmental benefits as it eliminates the earlier requirements for reactions to be in solution. In an early example of an on-water reaction, Novartis chemists achieved a $98 \%$ yield of triazole 65 from an onwater Huisgen 3+2 cycloaddtion reaction of 2,6-dichlorobenzyl azide 63 with 2-chloroacrylonitrile 64, on the route to the anticonvulsant rufinamide 66 (Scheme 17$).^{48}$ In organic solvents the reaction gave a $40 \%$ yield and this was limited by the $\mathrm{HCl}$ produced which caused polymerization of the acrylonitrile. The on-water approach gave a biphasic medium where the $\mathrm{HCl}$ was removed into the water layer, while the organic layer floated and reacted on-water.<smiles>NCc1c(F)cccc1F</smiles>

63

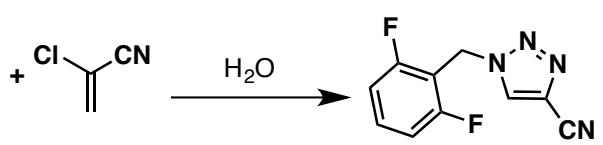

64
65

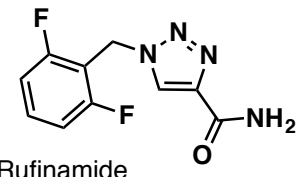

66

Scheme 17: Huisgen 3+2 cycloaddition reaction on-water for the synthesis of a Rufinamide intermediate. $^{48}$

\section{(b) Multicomponent reactions}

Multicomponent reactions are synthetically useful reactions as highly functionalized compounds can be synthesized all in one-pot. Vigalok and co-workers examined the Passerini reaction using a range of inand on-liquid conditions. ${ }^{49,50}$ Interestingly the reaction of acetaldehyde 67 , acetic acid 68 and isocyanide 69 in $\mathrm{CD}_{3} \mathrm{OD}$ and Benzene- $\mathrm{d}^{6}$ which gave poor yields $(<5 \%)$ however, in other liquids such as $\mathrm{C}_{8} \mathrm{~F}_{18}$ and neat mercury yields of $89 \%$ and $91 \%$ were observed respectively, which are higher than for the reaction on- $\mathrm{D}_{2} \mathrm{O}(44 \%)$ (Scheme 18a). The rate accelerations were proposed to arise from the cohesive energy density of these liquids, which are higher than water.

(a)

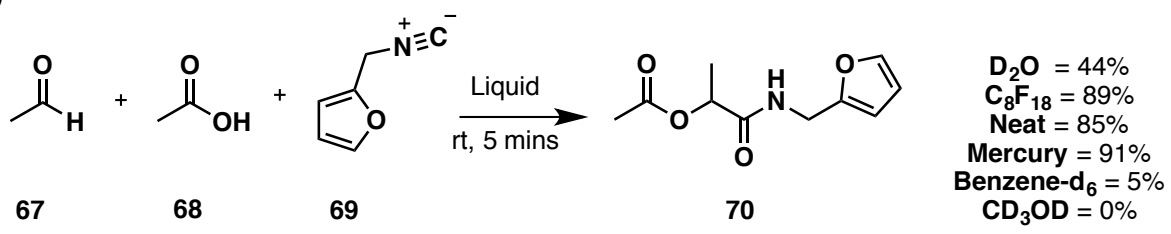

(b)<smiles>Cc1c(C)c2c(c(C)c1O)CCC(C)(C(=O)O)O2</smiles>

71<smiles>C=[N+](C)CCc1ccccc1</smiles>

72

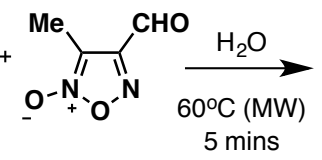

73<smiles></smiles>

74 
Scheme 18. Passerini three component reactions under on-water conditions. ${ }^{49-51}$

Porcal and López examined the Passerini reaction of furoxan aldehyde 73, phenylethylisocyanide 72 and trolox 71 using on-water reaction conditions, (Scheme 18b). ${ }^{51}$ They found that the reaction using water as a solvent gave a yield of $62 \%$ in 5 minutes under microwave conditions at $60^{\circ} \mathrm{C}$. The corresponding reaction under the same conditions using acetonitrile as a solvent gave a yield of $64 \%$ over 10 minutes showing that there was only a small increase in the rate of reaction using the on-water methodology.

\section{(c) Aldol type reactions}

The aldol reaction is a classic reaction in synthetic organic chemistry and is a key method for the synthesis of carbon-carbon bonds. There has been numerous reports using water as a solvent for aldol and aldol-type reactions however many of these have been carried out under organo- and metal catalysed conditions. ${ }^{52,53}$ Examples of uncatalysed Aldol reaction using on-water methodology are rare.

Zhang and Fan examined the Henry (nitroaldol) reaction of 4-chlorobenzaldehyde 75 with 3,5dimethyl-4-nitroisoxazole using on-water conditions. ${ }^{54}$ The products of the reaction 77 and 78 were isolated in a yield of $92 \%$ and $6 \%$ respectively over 15 hours. No reaction was observed in organic solvents such as toluene, DCM, THF and polar solvents such as $\mathrm{MeOH}$ gave only a yield of $30 \%$ of product 77 (Scheme 19a).

Dash and co-workers examined the uncatalysed aldol reaction of thiazolidinedione $\mathbf{7 9}$ and isatin 80 using on-water conditions, (Scheme 19b). ${ }^{55}$ The products $\mathbf{8 1}$ and $\mathbf{8 2}$ were isolated in a yield of $98 \%$ over 10 minutes. The anti/syn selectivity was $88: 12$, and subsequently when the reaction was allowed stir for 2 hours the yield remained at 98\% however the anti/syn selectivity increased to 98:2. The reaction was straightforward to carry out where the highly coloured isatin $\mathbf{8 0}$ could be seen disappearing over time and the product could be isolated by filtration with a purity $>99 \%$, which limits the use of organic solvents for extraction.

SaiPrathima and co-workers examined the Henry reaction of isatin $\mathbf{8 3}$ and nitromethane using the on-water conditions. ${ }^{56}$ The reaction gave a conversion of $98 \%$ after 30 minutes however using organic solvents such as IPA, DMF, THF, MeOH the conversions were $<40 \%$ after 60 hours showing that using the on-water conditions significantly decreased the reaction time. 
(a)<smiles>O=Cc1ccc(Cl)cc1</smiles>

75<smiles>Cc1noc(C)c1[N+](=O)[O-]</smiles>

76

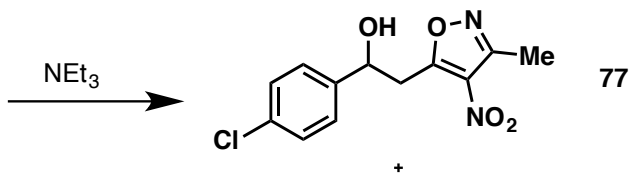<smiles>Cc1noc(/C=C/c2ccc(Cl)cc2)c1[N+](=O)[O-]</smiles>

(b)<smiles>CN1C(=O)CSC1=O</smiles><smiles>CN1C(=O)C(=O)c2ccccc21</smiles><smiles>CN1C(=O)S[C@H](C2(O)C(=O)N(C)c3ccccc32)C1=O</smiles><smiles>CN1C(=O)SC(C2(O)C(=O)N(C)c3ccccc32)C1=O</smiles>

$\mathrm{H}_{2} \mathrm{O} 10 \mathrm{~min}, 98 \%$ (88:12) $\mathrm{H}_{2} \mathrm{O} 2 \mathrm{~h}, 98 \%$ (98:2) DMF $24 \mathrm{~h}, 75 \%$ (88:12)

$\mathrm{H}_{2} \mathrm{O} \quad 92 \%: 6 \%(15 \mathrm{~h})$ DMF 3\%:0\% (24h) MeOH 30\%:0\% (24h)

(c)

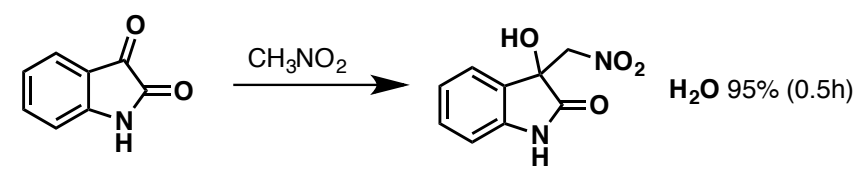

83

Scheme 19: Aldol and Nitro aldol reactions 'on-water'. ${ }^{54-56}$

Zhou, Wang and co-workers examined the Mukaiyama aldol reaction and the influence of fluorine substituents for on-water conditions. ${ }^{57}$ They examined the reaction of 4-chlorobenzaldehyde with a range of substituted silyl enol ethers, Scheme 20. The reaction of the silyl enol ether 86 with 4chlorobenzadehyde $\mathbf{7 5}$ gave only trace amounts of $\mathbf{8 5}$ with almost complete hydrolysis of 86 encountered. Introduction of a fluorine onto the silyl enol ether $\mathbf{8 7}$, gave a slow reaction with a product yield of $26 \%$. However with the difluoroinated silyl enol ether $\mathbf{8 9}$ the product was formed in $85 \%$ even though the reactant 89 is more susceptible to hydrolysis than $\mathbf{8 6}$. A further extension of this methodology explored an asymmetric version using the $(\mathrm{QD})_{2} \mathrm{Pyr}$ catalyst and the yields were higher using water as a medium although there was a drop in the enantioselectivity of the reaction in comparison to THF, (Scheme 20b). 
(a)

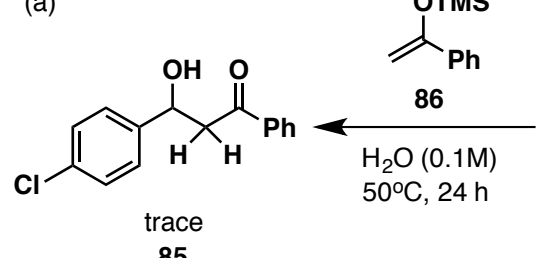

85<smiles>O=Cc1ccc(Cl)cc1</smiles>

75

$\left.$\begin{tabular}{l|l}
$\mathrm{H}_{2} \mathrm{O}(0.1 \mathrm{M})$ \\
$50^{\circ} \mathrm{C}, 10 \mathrm{~h}$
\end{tabular}\right|$_{\mathbf{F}} ^{\mathrm{F}_{\mathbf{P h}}}$

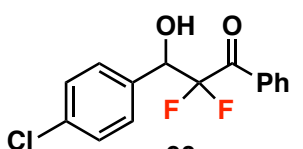

90

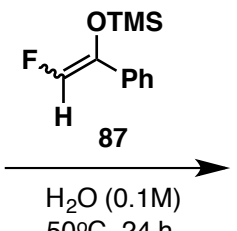

$\mathrm{Cl}$

$26 \%$ (NMR Yield)

88 (b)<smiles>O=Cc1ccc(Cl)cc1</smiles><smiles>COC(=O)C(OC)=C(F)P</smiles>

(2.0 eq)

$\mathrm{H}_{2} \mathrm{O}\left(10 \mathrm{~mol} \%\left(\mathrm{QD}_{2}\right) \mathrm{Pyr}\right)$ $73 \%(39 \%$ ee $)$

THF (10 mol\% $\left.\left(\mathrm{QD}_{2}\right) \mathrm{Pyr}\right)$ $15 \%(67 \%$ ee $)$ (c)

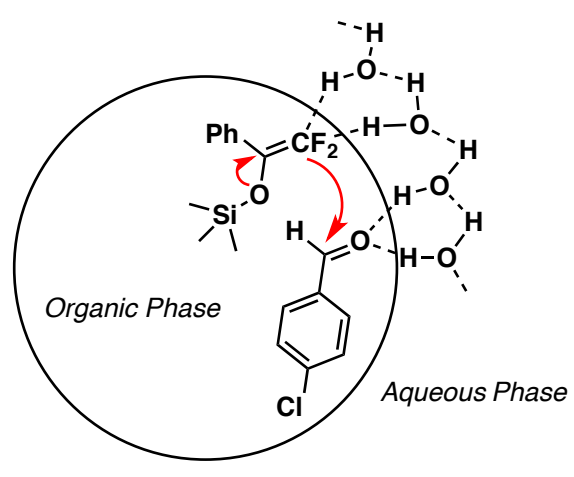

Scheme 20: Mukaiyama aldol reaction 'on-water',57

Wang, Zhou and co-workers proposed that the acceleration for the fluorinated silyl enol ethers was due to favorable $\mathrm{C}-\mathrm{FS}^{-}--\delta^{+} \mathrm{H}-\mathrm{O}$ interactions at the water-organic phase boundary giving $\mathrm{H}$-bond activation of the electrophile and increasing the reaction rate (Scheme 20c). The non-fluorinated silylenol ethers were unable to attain this catalytic interaction.

\section{(d) Organometallic and Transition Metal Catalysed Reactions}

Recently Capriati and co-workers have opened a new unexpected dimension for on-water organic synthesis that has huge potential. ${ }^{58}$ When about 3 molar equivalents of Grignard reagents in THF solution, or organolithium reagents in diethyl ether solution were rapidly spread over suspensions of $\gamma$-chloroketones 91 on-water, under air at room temperature, rapid high yielding reactions occurred giving mixtures of chlorohydrins 94 and their cyclisation product 95 (Scheme 21) 


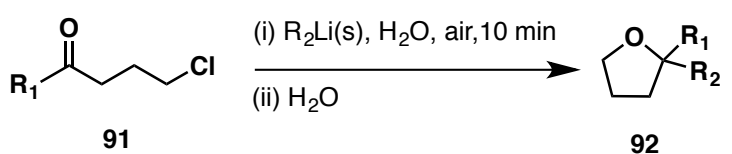

$50-75 \%$ Yields

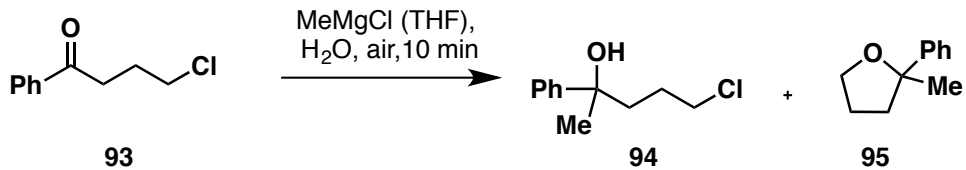

Scheme 21: Grignard and organolithium reactions on-water ${ }^{58}$

The presence of water or air would normally be considered fatal for such reactions. Strictly anhydrous conditions could have been considered to be essential. The quantity of liquid water present needed to be carefully controlled and under optimized conditions at laboratory or batch scales significantly better conversion yields were obtained than in anhydrous organic media with little or no protolysis of the organometallic reagents. Small $\mathrm{D} / \mathrm{H}$ isotope effects were observed for reactions on $-\mathrm{D}_{2} \mathrm{O}$. Interfacial $\mathrm{H}$ bonding to the water-insoluble ketones embedded at the organic-water interface is considered to provide catalytic impetus.

Transition metal catalysis is a vast area of research with a multitude reaction types included in this category. ${ }^{59}$ The use of on-water conditions for these reactions can be complex as the stability of metal and metal-ligand complexes need to be taken into consideration and some reactions have proven more successful than others.

Lu and co-workers examined the rhodium(III) catalysed $\mathrm{C}-\mathrm{H}$ monoamination of arenes using on-water conditions. ${ }^{60}$ The reaction of 2-phenylpyridine 96 and 1-azido-4-nitrobenzene 97 was carried out using $\left[\mathrm{RhCp}^{*} \mathrm{Cl}_{2}\right]_{2}$ and NaBARF as an additive. The reaction when carried out at $110^{\circ} \mathrm{C}$ with $4 \mathrm{~mol} \%$ of NaBARF gave compound 98 in a yield of $99 \%$ (Scheme 22a). Exploration of the reaction using organic solvents such as DCE, 1,4-dioxane, toluene, DMF, DMSO, hexane and isopropanol under identical conditions gave yields of $<10 \%$. It was found that water played two critical role in the reaction, firstly it helped form the intermediate rhodacycle which is the active intermediate and the $\mathrm{OH}$ groups present on the hydrophobic interface helps to abstract a proton. Secondly it helps the rollover step possibly through the intramolecular $\mathrm{H}$-bonding. When carried out using organic solvents these steps are not as efficient.

The Kinugasa reaction was developed in the 1970's and it involves the copper-catalysed reaction of a nitrone with a terminal alkyne. ${ }^{61}$ However, rather than a $3+2$ cycloaddition reaction where a five membered heterocyclic ring is synthesized in this reaction a four membered $\beta$-lactam ring is formed through rearrangement of the initial cycloadduct. This is a synthetically useful reaction as both nitrones and terminal alkynes are readily available and the $\beta$-lactam rings are key heterocycles found in 
medicinal chemistry. Feng, Liu and co-workers examined the reaction of phenyl acetylene 99 and $\mathrm{N}$ substituted nitrones 100 using a chiral copper-diamine complex under base catalysed conditions. ${ }^{62}$ The combination of $\mathrm{Cu}(\mathrm{OTf})_{2}$ and the chiral diamine ligand with the $n \mathrm{Bu}_{2} \mathrm{NH}$ in water generated a blue precipitate. Upon the addition of the phenyl acetylene $\mathbf{9 9}$, a yellow oil was observed which floated on top of the water (Scheme 22b). Two products, trans and cis isomers, were isolated from the reaction in yields of up to $83 \%$. A trans:cis ratio of $99: 1$ was observed and the ee of the trans isomer was $90 \%$. When the reaction was carried out in acetonitrile a comparable yield (88\%) was observed however a drop in diastereo- and enantioselectivity (83:17, ee trans $78 \%$ ) was observed when compared to those on-water.

(a) Rhodium Catalysed Reactions

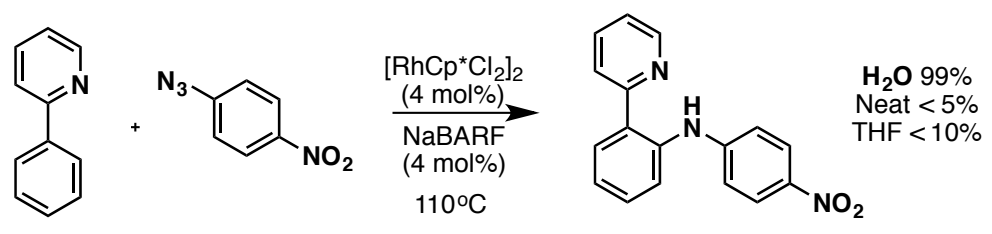

96

97

98

(b) Copper Catalysed Reactions<smiles>C#CPc1ccccc1</smiles>

99

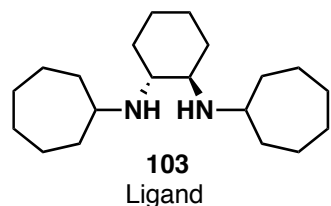

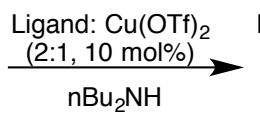
$\mathrm{nBu}_{2} \mathrm{NH}$

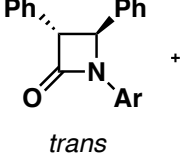

101

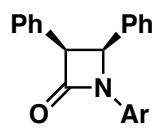

cis

102

Diglycol $71 \%$, (97:3), 93\% ee (cis)

MeCN 88\%, (83:17), 78\% ee (cis)

Neat $86 \%,(94: 6), 91 \%$ ee (cis)

$\mathrm{H}_{2} \mathrm{O} 83 \%$, (99:1), $90 \%$ ee (cis)

(c) Palladium Catalysed Reactions<smiles>C#C[Si](C(C)C)(C(C)C)C(C)C</smiles>

104<smiles>C=C(C(=O)OC)C(OC(C)=O)c1ccccc1</smiles>

105

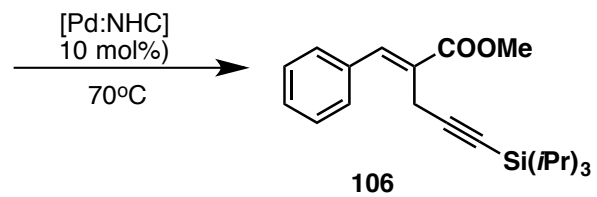

THF 20\% DMF $4 \%$ 1,4-Dioxane $23 \%$ $\mathrm{H}_{2} \mathrm{O} 71 \%$

Scheme 22: Transition metal catalysed reactions using on-water conditions. ${ }^{60,62,63}$

Palladium catalysed reactions are some of the most important reactions in organic chemistry and include reactions such as the Suzuki, Heck, Sonogashira, Tsuji-Trost reactions. While water has been routinely used as a co-solvent in Suzuki coupling reactions the use of water in other palladium- 
catalysed reactions has not been as widespread and is still an emerging area of research. Liu and coworkers examined the palladium-catalysed alkynylation of Morita-Balyis-Hillman carbonates with substituted acetylenes using on-water conditions. ${ }^{63}$ A range of ligands were examined for the reaction and the $[\mathrm{Pd}: \mathrm{NHC}] 107$ was found to give the optimum yield (Scheme 22c). When the reaction of triisopropylsilaneacetylene 104 was reacted with compound 105 in THF the product was isolated in a yield of $20 \%$. When the reaction solvent was changed to more polar solvents such as DMF and 1,4dioxane the yields were found to be $4 \%$ and $23 \%$ respectively. Exploring the reaction using on-water conditions the product was isolated in $71 \%$ yield, a signigicant increase in yield compared to organic solvents.

\section{(e) Organocatalysis}

The emergence of organocatalysis in the late 1990's offered an alternative catalytic method for organic reactions. In some of the first reported reactions by MacMillan, List and Barbas, water was used as the co-solvent. ${ }^{64,65}$ Organocatalysis involves the use of sub-stiochiometric amounts of an organic compound to catalyse a reaction. The mode of activation depends upon the catalyst and this can be through covalent activation through the formation of an enamine and imine bond (e.g. proline organocatalysts) or through hydrogen-bond activation (e.g. thiourea H-bonding organocatalysts). The use of water as a solvent has prompted debate as to whether reactions occur on-water, in-water or in the presence of water. However the true nature of these reactions need further in-depth mechanistic study to determine the exact role water plays. ${ }^{66}$

The use of water in organocatalysis has been extensively reviewed in the literature and select examples will be discussed herein. ${ }^{67,68,69}$ Ghosh and co-workers explored the on-water organocatalysed Diels-Alder [4+2] cycloaddition reaction of enones and nitrodienes (Scheme 23a). ${ }^{70}$ The organocatalyst 112 was based on the cinchona alkaloid scaffold where the primary amine of $\mathbf{1 1 2}$ forms an enamine and iminium covalent bond with the ketone group of the $\alpha, \beta$-unsaturated ketone 108 , this then undergoes a [4+2] cycloaddition reaction with the nitrodiene 109, although a double Michael addition pathway is also possible as a mechanistic rationale for the formation of the product 110 and 111 . When the reaction was explored in organic solvents such as $\mathrm{MeOH}$ and THF the reaction took 5 days to go to completion and the products were formed in moderate yields. The enantioselectivity was found to be excellent with ee's up to $94 \%$ observed. Upon changing the solvent to water the rate of the reaction increased and was found to go to completion in 2 days. It was observed that both the reactants and catalyst were insoluble when water was used solvent. The selectivity of the reaction was found to have increase to $1: 4$ $(110: 111)$ and the enantioselectivity of the reaction also increased where an ee's of $>98 \%$ was observed. 
(a)<smiles>CC(=O)/C=C/c1ccccc1</smiles><smiles>CCN1C2CCC1N(CC)C2[C@H](N)c1ccnc2ccc(OC)cc12</smiles>

THF: 5 days, $41 \%, \alpha: \beta 1: 1$, ee( $\beta) 92 \%$

MeOH: 5 days, $32 \%, \alpha: \beta 1: 1$, ee( $\beta) 94 \%$

$\mathbf{H}_{\mathbf{2}} \mathbf{O}: 2$ days, $75 \%, \alpha: \beta 1: 4$, ee $(\beta)>98 \%$

(b)

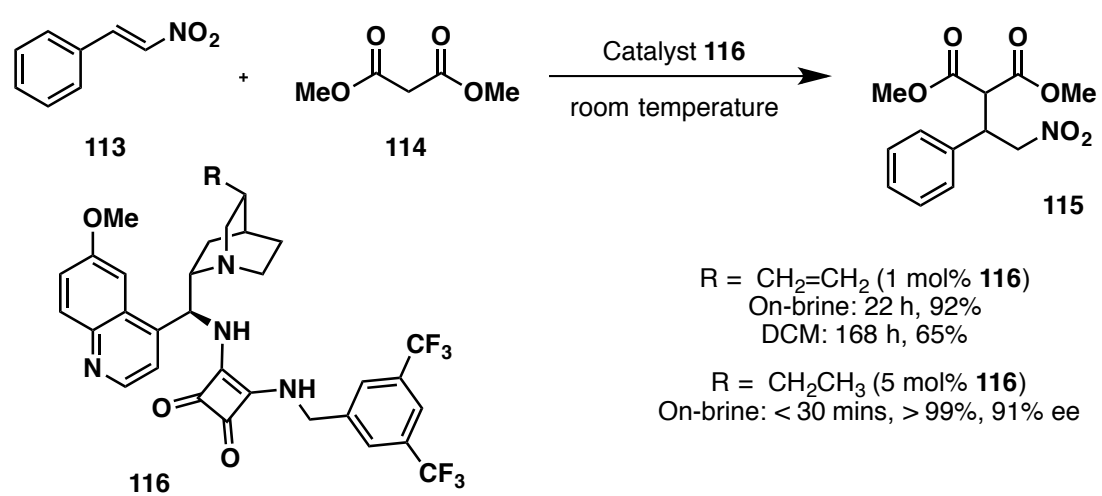

(c)
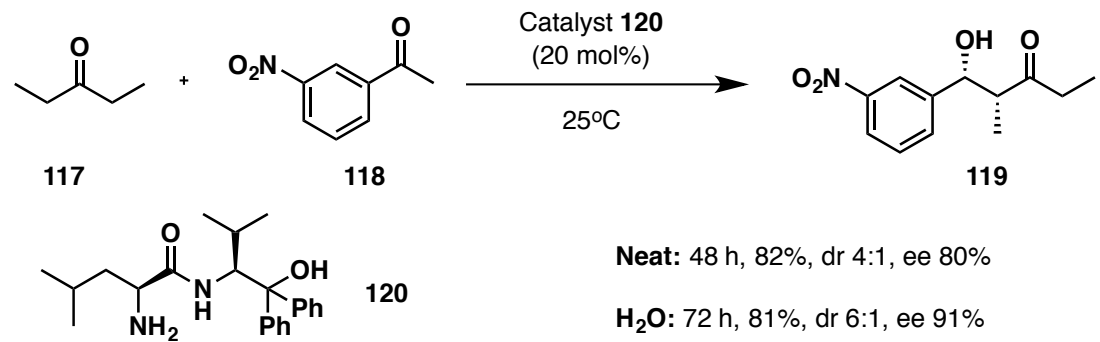

Neat: 48 h, $82 \%$, dr $4: 1$, ee $80 \%$

$\mathrm{H}_{2} \mathrm{O}: 72 \mathrm{~h}, 81 \%$, dr 6:1, ee $91 \%$

Scheme 23: Organocatalysed reactions using on-water conditions. ${ }^{70-72}$

Song and Bae examined the organocatalytic Michael addition reaction of malonates to nitroalkenes using a chiral squaramide H-bonding organocatalyst 116 (Scheme 23b). ${ }^{71}$ The reaction of nitrostyrene 113 and the $\beta$-ketoester 114 in DCM gave the products in 65\% after 168 hours. Changing the solvent to brine the reaction went to completion in 22 hours and in a yield of $92 \%$. The authors observed by making a small change to the organocatalyst 116 where the vinyl group on the bicyclo[2,2,2] ring was reduced to an ethyl group this increased the hydrophobicity of the catalyst in the aqueous environment and this gave an increase in the rate of reaction where the reaction went to completion in $<30$ mins and an increase in yield was observed to $>99 \%$ and the ee of the product was found to be $91 \%$.

Gong and co-workers examined the on-water organocatalytic aldol reaction of aldehydes and aliphatic ketones (Scheme 23c). ${ }^{72}$ The reaction was catalysed using a amino acid based organocatalyst 
120 which was used in $20 \mathrm{~mol} \%$. When the reaction was carried out under neat conditions (20 fold excess of 117) the reaction occurred in $82 \%$ yield over 48 hours with a moderate dr of $4: 1$ and an ee of $80 \%$. Upon changing the solvent to water this gave an increase in the reaction time to 72 hours however an increase in the $\mathrm{dr}$ to $6: 1$ and an increase in ee to $91 \%$ was observed. The organocatalyst catalyses the reaction through enamine formation with 118 however, the $\mathrm{NH}$ and $\mathrm{OH}$ have been postulated to form $\mathrm{H}$-bonding interactions with the ketone 117. This was supported by examination of a silyl protected $\mathrm{OH}$ catalyst and the conversion dropped to $5 \%$. Organocatalysis has emerged as a major area of research and ever since the first reports water has played a key role as ether the co-solvent or solvent. However these reactions needs further mechanistic study in order to elucidate the role water plays.

The focus of this review has centered on a handful of reaction types however, there has been an extensive array of reactions explored using the on-water methodology. One of the applications has been in the synthesis of heterocycles although these do not fall into any one reaction class. Chakraborti and co-workers have examined a wide range of reactions both in-water and on-water methodologies. In 2007 they reported the synthesis of a range of substituted benzothiazoles and benzothiazolines using on-water methodology. ${ }^{73}$ The products were isolated in good to excellent yields and there was a decrease in the reaction time in comparison to the reactions carried out in organic solvents. Charkraborti and co-workers examined further reactions for the synthesis of 1,5-benzothiazepines, and tetrahydropyridines using on-water methodologies. ${ }^{74,75}$

McErlean and co-workers have examined in-water/on-water methodologies applied to total synthesis. In 2013 they examined the synthesis of columbianetin containing natural products using a domino in-water/on-water process. A key step in the pathway was an aromatic Claisen rearrangement which gave excellent yields ${ }^{.76} \mathrm{~A}$ further in-water/on-water domino process was explored in 2015 where the McErlean and Norcott examined the synthesis of königinequinone A which offered a route to other natural products murrayquinone $B, C, D$ and $E$ though an on-water Claisen rearrangement. ${ }^{77}$

The scope of reactions which have been explored using on-water conditions continues to grow. and water can offer advantages over organic solvents. However, this is reaction specific and in many cases this is still an emerging area of research where in-depth mechanistic studies are needed in order to deduce the role water plays in these reactions.

\section{Conclusions}

Ever since the term 'on-water' was coined in 2005 a diverse range of reaction types have been explored using this methodology. However, mechanistically there still remain unanswered questions about specific reactions, echoing the comment of Jung and Marcus that "every reaction is a special 
case". In this review we have examined a range of reaction types and explored the mechanistic aspects of these on-water reactions. We hope that this provides an impetus to explore further the synthetic value and mechanistic puzzles of on-water reactions and that it provides insight into the distinctions which exist between reactions on-water and in-water.

${ }^{\dagger}$ Richard N. Butler, Professor of Chemistry (1980-2008), Emeritus Professor of Chemistry (2008-2016) NUI Galway, passed away on the $10^{\text {th }}$ February 2016.

\section{References}

1) S. Narayan, J. Muldoon, M.G. Finn, V.V Fokin, H.C. Kolb, and K. B. Sharpless, Angew. Chem. Int. Ed. 2005, 44, 3275-3279.

2) D. C. Rideout, and R. Breslow, J. Am. Chem. Soc. 1980, 102, 7816-7817.

3) R. Breslow, Acc. Chem. Res. 1991, 24, 159-164.

4) R. Breslow, Acc. Chem. Res. 2004, 37, 471-478.

5) W. M. Lindström, Organic Reactions in Water: Principles, Strategies and Applications, $1^{\text {st }}$ Ed.; Blackwell Publishing, Oxford, 2007.

6) P. P. Garner, Organic Synthesis in Water, Grieco, P.A. Ed., Blackie Academic and Professional: London, 1998 p. 1-141.

7) A. Chanda, and V. V. Fokin, Chem. Rev. 2009, 109, 725-748.

8) C. J. Li, Chem. Rev., 2005, 105, 3095-3165.

9) J. B. F. N. Engberts and M. J. Blandamer, Chem. Commun., 2001, 1701-1708.

10) R. N. Butler and A. G. Coyne, Chem. Rev., 2010, 110, 6302-6337.

11) Kobayashi, S. Water in Organic Synthesis. Science of Synthesis Workbench Edn., Thieme, Stuttgart, 2012.

12) M. C. Pirrung, Chem. Eur. J. 2006, 12, 1312-1317.

13) R. I. Khusnutdinov and T. M. Oshnyakova, Tetrahedon Lett., 2015, 56, 6386-6369.

14) R. N. Butler, A. G. Coyne and E. M. Moloney, Tetrahedron Lett., 2007, 48, 3501-3503

15) K. D. Beare, and C. S. P. McErlean, Tetrahedron Lett., 2013, 54, 1056-1058. 
16) K. D. Beare, A. K. L. Yuen, A. F. Masters, T. Maschmeyer, and C. S. P. McErlean, Chem Commun, 2013, 49, 8347-8349.

17) R. N. Butler, A. G. Coyne, W. J. Cunningham and E. M. Moloney, J. Org Chem., 2013, 78, 3276-3291.

18) R. N. Butler and A. G. Coyne, J. Org. Chem., 2015, 80, 1809-1817.

19) J. Alsenz and M. Kansy, Adv. Drug Delivery Rev., 2007, 59, 546-567

20) A. J. Hopfinger, E. X. Esposito, A. Llinas, R. C. Glen and J. M. Goodman, J. Chem. Inf. Model., $2009,49,1-5$.

21) M. C. Pirrung, K. D. Sarma and J. Wang, J. Org. Chem., 2008, 73, 8723-8730.

22) D. Guo, D. Zhu, X, Zhou and B. Zheng, Langmuir, 2015, 31, 13759-13763.

23) S. Mellouli, L. Bousekkine, A.B. Theberge and W.T.S. Huck, Angew Chem. Int. Ed. 2012, 51, 7981-7984.

24) S. Otto and J. B. F. N. Engberts, Org. Biomol. Chem. 2003, 1, 2809-2820.

25) A. Meijer, S. Otto and J. B. F. N. Engberts, J. Org. Chem., 1998, 63, 8989-8994.

26) J. F. Blake, D. Lim, and W. L. Jorgensen, J. Org. Chem., 1994, 59, 803-805.

27) D. Van Mersbergen, J. W. Wijnen and J. B. F. N. Engberts, J. Org. Chem., 1998, 63, 88018805.

28) T. Rispens and J. B. F. N. Engberts, J. Phys. Org. Chem., 2005, 18, 908-917.

29) R. N. Butler, W. J. Cunningham, A. G. Coyne and L. A. Burke, J. Am. Chem. Soc., 2004, 126, 11923-11929.

30) O. Acevedo and K. Armacost, J. Am. Chem. Soc., 2010, 132, 1966-1975.

31) Y. Jung and R. A. Marcus, J. Am. Chem. Soc., 2007, 129, 5492-5502.

32) L. L. Thomas, J. Tirado-Rives and W. L. Jorgensen, J. Am. Chem. Soc., 2010, 132, 3097-3104.

33) Y-J, Zuo and J. Qu, J. Org. Chem., 2014, 79, 6832-6839.

34) J. G. Davis, B. M. Rankin, K. P. Gierszal and D. Ben-Amotz, Nature Chem. 2013, 5, 796-802. 
35) J. K. Beattie, C. S. P. McErlean and C. B. W. Philippen, Chem. Eur. J., 2010, 16, 8972-8974.

36) J. March, Advanced Organic Chemistry: Reaction Mechanisms and Structures, $4^{\text {th }}$ Ed. John Wiley and Sons Inc: New York, 1992; (a) pp. 226-230; (b) pp. 250-253 (the basic pKa of alkylaryl amines is ca. 3-5 and azo compounds is ca. 2).

37) K. Karhan, R. Z. Khaliullin and T. D. Kühne, J. Chem. Phys. 2014, 141, 22 D528 (doi: 10.1063/1.4902537)

38) J. K. Beattie, A. M. Djerdjev and G. G. Warr, Faraday Discuss. 2009, 141, 31-39.

39) J. K. Beattie, Colloid stability - The role of surface forces, Part II, Vol 2, Ed. Tadras, T.; WileyVCH, Weinheim, 2007, p. 153.

40) K. D. Beare, and C. S. P. McErlean, Org. Biomol. Chem., 2013, 11, 2452-2459.

41) L. R. Domingo, J. A. Saéz, R. J. Zaragozá and M. Arnó, J. Org. Chem. 2008, 73, 8791-8799.

42) P. G. Cozzi and L. A. Zoli, Angew. Chem. Int. Ed. 2008, 47, 4162-4166.

43) F-Z, Zhang, Y. Tian, G-X Li and J. Qu, J. Org. Chem., 2015, 80, 1107-1115.

44) Z-B. Xu and J. Qu, Chem. Eur. J., 2013, 19, 314-323.

45) R. N. Butler, A. G. Coyne, W. J. Cunningham, E. M. Moloney and L. A. Burke, Helv. Chim. Acta, 2005, 88, 1611-1629.

46) J. M. de los Santos, R. Ignacio, Z Es Sbai, D. Aparicio and F. Palacios, J. Org Chem., 2014, 79, 7607-7615.

47) M. V. Gil, V. Luque-Agudo, E. Román and J. A. Serrano, Synlett, 2014, 25, 2179-2183.

48) R. Portmann, WO Patent 9802423, 1998.

49) T. Sela, A. Vigalok, Org. Lett., 2014, 16, 1964-1967.

50) T. Sela, A. Vigalok, A. Adv. Synth. Catal., 2012, 354, 2407-2411.

51) M. Ingold, G. V. López and W. Porcal, ACS Sustainable Chem. Eng, 2014, 2, 1093-1097.

52) C. Jimeno, Org. Biomol. Chem., 2016, 14, 6147-6164

53) J. Mlynarski and S. Bas, Chem. Soc. Rev., 2014, 43, 577-587. 
54) Y. Zhang, B-W. Wei, L-N, Zou, M-L, Kang, H-Q, Luo and X-L. Fan, Tetrahedron, 2016, 72, $2472-2475$.

55) S. Paladhi, M. Bhati, D. Panda and J. Dash, J. Org. Chem., 2015, 79, 1473-1480.

56) P. SaiPrathima, K. Srinivas and M. M. Rao, Green Chem., 2015, 17, 2339-2343.

57) J-S. Yu, Y-L. Liu, J. Tang, X. Wang and J. Zhou, Angew. Chem. Int. Ed. 2014, 53, 9512-9516.

58) L. Cicco, S. Sblendorio, R. Mansueto, F.M. Perna, A. Salomone, S. Florio and V.Capriati. Chem. Sci., 2016, 7, 1192-1199.

59) B. Cornils and W. A. Herrmann (Ed), Aqueous-Phase Organometallic chemistry: Concepts and Applications, Wiley-VCH, 2006.

60) M.A. Ali, X. Yao, G. Li and H. Lu, Org. Lett, 2016, 18, 1386-1389.

61) M. Kinugasa and S.J. Hashimoto, J. Chem. Soc. Chem. Commun, 1972, 466-467.

62) Z. Chen, L. Lin, M. Wang, X. Liu and X. Feng, Chem. Eur. J., 2013, 19, 7561-7567.

63) Y. Li, L. Liu, D. Kong, D. Wang, W. Feng, T. Yue and C. Li, J Org. Chem., 2015, 80, 6283-6290

64) K. A. Ahrendt, C. J. Borths and D. W. C. MacMillan, J. Am. Chem. Soc., 2000, 122, 4243-4244.

65) B. List, R. A. Lerner and C. F. Barbas III, J. Am. Chem. Soc., 2000, 122, 2395-2396.

66) N. Mase and C. F. Barbas III, Org. Biomol. Chem., 2010, 8, 4043-4050.

67) M. Raj and V. K. Singh, Chem. Commun., 2009, 6687-6703.

68) S. Bhowmick, A. Mondal, A. Ghosh and K. C. Bohwmick, Tetrahedron Asymm., 2015, 26, $1215-1244$.

69) C. Timeno, Org. Biomol. Chem., 2016, 14, 6147-6164.

70) G.B. Vamisetti, R. Chowdhury, M. Kumar and S.K. Ghosh, Org. Lett., 2016, 18, 1964-1967.

71) H. Y. Bae and C. E. Song, ACS Catal., 2015, 5, 3613-3619.

72) M-K. Zhu, X-Y. Xu and L-Z. Gong, Adv. Synth. Catal., 2008, 350, 1390-1396.

73) A.K. Chakraborti, S. Rudrawar, K. B. Jadhav, G. Kaur and S.V. Chankeshwara, Green Chem., $2007,9,1335-1340$. 
74) G. Sharma, R. Kumar and A. K. Chakraborti, Tetrahedron Lett., 1998, 49, 4269-4271.

75) N. Parikh, S. R. Roy, K. Seth, A. Kumar and A. K. Chakraborti, Synthesis, 2016, 48, 547-556.

76) K. D. Beare and C. S. P. McErlean, Tetrahedron Lett., 2013, 54, 1056-1058.

77) P. Norcott and C. S. P. McErlean, Org. Biomol. Chem., 2015, 13, 6866-6878.

\section{Author Biographies}

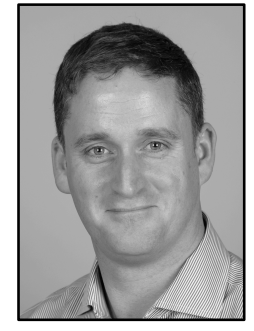

Anthony G. Coyne received his B.Sc (Hons) (1998) and PhD (2002) from the National University of Ireland, Galway. His Ph.D work focused on the synthetic and mechanistic aspects of the Huisgen cycloaddition reactions using water as a solvent. He then moved to an industrial position with GlaxoSmithKline followed by postdoctoral positions at University College Dublin and the University of Cambridge.

His current position is as a Senior Research Associate at the Department of Chemistry, University of Cambridge. His current research interests are at the interface of chemistry and biology focusing on using small molecules to probe biological functions.

Richard N. Butler holds degrees of B.Sc. (1964), Ph.D (1967) (University College Cork), and research D.Sc. (1974) of the National University of Ireland. Awarded an Overseas Scholarship by the Royal Commission for the Exhibition of 1851, he carried out postdoctoral work in

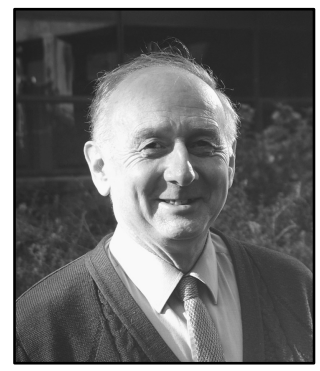
physical chemistry at the University of Leicester (1967-1969) studying solvation phenomena using magnetic resonance spectroscopy. Returning to organic chemistry he worked on synthesis and mechanism with organic nitrogen molecules. He was a lecturer and associate professor at University College Galway (later, National University of Ireland Galway) from 1971-1981 and Professor of Chemistry and Head of the Chemistry Department (later, School of Chemistry) from 1981 to 2008. He was elected a Member of the Royal Irish Academy in 1979, President of the Institute of Chemistry of Ireland (1986-1988), and Chair of the Royal Society of Chemistry, Republic of Ireland Section, (1993-1996). 